Folia Primatol 1996;67:221

\title{
Author Index Vol. 67, 1996
}

The authors of the abstracts of the Scientific Meeting of the Italian Primatological Society, La Société Française de Primatologie and the Primate Society of Great Britain are indexed separately in Vol. 67, No. 2, 1996

Aeschlimann, C. 52 Anzenberger, G. 52

da Suva, M.N.F. 113

Feistner, A.T.C. 44

Holenweg, A.-K. 125

Kirkpatrick-Tanner, M. 52

Le Minor, J.M. 182 Luboga, S.A. 15 Lynch, J.M. 15

Montagnon, D. 157

Noë, R. 125

Oda, R. 40

Patton, J.L. 113 Peres, C.A. 113

Rumpler, Y. 157

Schaaf, A. 182 Schabel, M. 125 Schmitt, D. 137

Schmittbuhl, M. 182 Sellers, W.I. 1 Steenbeek, R. 169

Taylor, T.D. 44

Treves, A. 152

Ungar, PS. 163 Wood, C.G. 15 Youlatos, D. 193

221 